\title{
Reflections on the Evaluation of Practical Teaching in the NCO Academy
}

\author{
Zhongmin Liu, Zelong Zhou, Xiaojia Gu, Yun Liu, Qiong Zou \\ Wuhan Mechanical College, Army Engineering University, Wuhan, 430075, China
}

Keywords: NCO Academy, Practical teaching, Evaluation system

\begin{abstract}
The practical teaching link of the NCO is an important part of the sergeant teaching, which is directly related to the realization of the training goal of the sergeant. At present, most of the sergeant colleges and universities have begun to pay attention to the practice teaching, but there are still some Sergeant colleges and universities that do not build a corresponding practical teaching system. Based on the current situation of NCO education practice teaching, this paper expounds the connotation of NCO practice teaching system, and constructs a practical teaching system to improve the quality of NCO education practice teaching.
\end{abstract}

\section{Paying attention to clarifying several misunderstandings of practical teaching}

The promotion of practical teaching is an important direction for the development of teaching and the innovation of teaching law in the Academy of sergeant. In order to improve teaching quality and give full play to the advantages of practical teaching in NCO training and achieve transformation from knowledge base to competency based standard, we must establish systematic and perfect models and methods in order to provide correct guidance and promotion for teaching.

Since the implementation of practical teaching, Sergeant colleges have begun to promote the construction of practical teaching evaluation, but in specific practice, the effect is not satisfactory. There are still many misunderstandings in the current teaching evaluation mode. Misunderstanding one: deliberate professional training to avoid classroom teaching. In practice teaching, many colleges and universities advocate the professional training mode vigorously in the evaluation, minimize and avoid classroom lecturing teaching mode, and enter the misunderstanding of teaching evaluation. The reason is that the current understanding of the connotation of practical teaching is too narrow. The practice teaching is equivalent to the training teaching. In order to achieve the requirement of "practice teaching occupies more than $60 \%$ of the whole teaching process", a trend of "practice alone" is formed. Practice teaching should have the connotation of a more generalized, can guide the students to better grasp the gist of practice, to improve the practical ability of teaching, should belong to the practical teaching, and should not be simply interpreted as "training", in order to improve the students skill of experience teaching is a practical teaching, students of physical display visual impression is practice teaching, strengthen students' practical situational training is the practical teaching, to consolidate the formulation of the work is to practice teaching. In the teaching evaluation, the "60\% indicators" of practical teaching should be taught and flexible. Misunderstanding two: focus on the ability to abandon the basic theory. Since the popularization of practical teaching, erroneous zones of practice teaching need no theory have been gradually formed in teaching evaluation, encouraging unilateral practice and training in practice, and compressing and cancelling the teaching of basic theory. The reason is that the evaluation of positioning is not allowed, the rapid success and short profit, no long-term development of the students. Practice is not only an operation, but practice is not only a skill, but practice should be a kind of ability. In many cases, there is no theoretical foreshadowing. Students only meet with one thing, do not understand divergent analogy, only learn rote memorization, do not understand the rule of law, but simply inherit, do not understand innovation. The theory is not useless, but to see how to make a choice, Sergeant education practice teaching to theoretical teaching, but should be doing, Jingjiang more training, combined with practice, focusing on the development, rather than the "practice" and "theory" is completely separated. The sergeant education should take the cultivation of students learning and innovation as the starting point, in order to improve the students ability and quality as 
the goal, the theory of knowledge accumulation and practical operation training combined with guidance, training, inspiration, this is the college teaching evaluation should determine the stations. Misunderstandings three: neglect the effect of teaching in the form of practice. The characteristics of practical teaching decide that there will be corresponding teaching reform in its promotion process. The innovation of teaching mode represented by practical training, situational teaching and small class teaching has obvious characteristics in form compared with the previous pure lecture teaching. It is easy to cause colleges often defined as a symbol of practice teaching in the teaching form in the teaching evaluation, the strength to pursue the classroom atmosphere, teaching organization, class type integration surface design, emphasis on form and ignore the actual effect of these new forms of the teaching mode of the. The ultimate goal of teaching is to cultivate talents, no matter what kind of teaching form, "lessons" is the due meaning, really improve the quality of talent training is the only criteria, not on the "show class", "class form", which have the order reversed. Therefore, in the field of education evaluation should focus on the implementation of practice teaching must take the teaching effect as the premise, that can really cause method and form the students' learning interest, enhance the brand, improve the operation ability of knowledge into teaching, must make the choice of the form of teaching to follow the law, serve the teaching goal.

\section{Scientific construction of practical teaching evaluation system}

The establishment of a scientific and complete evaluation system of practical teaching is the main means to promote the rapid improvement of the quality of practical teaching. Whether the result of practical teaching evaluation is objective and impartial, mainly depends on the selected evaluation index. So establishing a complete evaluation index system of practical teaching is the key to effective evaluation of practical teaching. The object of evaluation, mainly for students, teachers and security conditions, so the index system should include: a set of scientific and complete student evaluation index system, the evaluation index system of a set of comprehensive and effective teacher evaluation index system and a set of reasonable and fair security conditions. For students' assessment, they should mainly focus on "learning" evaluation, through curriculum and training project evaluation, closely linked to practical teaching objectives of curriculum and training projects, focusing on assessment and evaluation of students' vocational skills and professional qualities. To the teacher's evaluation should be used in the development of evaluation, namely, under the condition of respecting teachers to promote teacher professional development for the purpose of evaluation, through the development of evaluation based on the principle of objectivity, can make scientific and comprehensive evaluation for teachers, the final results back to the parties and personnel into the teacher appraisal system NCO academies. It is particularly important to examine the guarantee conditions, and should focus on the assessment of the guarantee resources, the guarantee process and the guarantee results of the practice teaching.

\section{Some suggestions on actively promoting the evaluation of practical teaching}

Advance of sergeant education practical teaching evaluation is a comprehensive system engineering, and it is not a point, the reform can be achieved in the premise, should fully understand the connotation of the teaching and practice of law, the traditional teaching evaluation standard as the basis, set the corresponding points, to promote interest in teaching as the starting point, in order to enrich the teaching methods for auxiliary, in order to strengthen the skills training as the starting point, with strict teaching management as the guarantee, enhance the guiding function of evaluation.

Firstly, based on the object of teaching, to cultivate interest teaching as a point of addition

Teaching is mutual, only teacher music teaching, student music, can realize the best teaching effect. Therefore, to improve the quality of teaching, we should not only do the article from the angle of the teacher, but also start with the training of the initiative of the students and "two aspects". The teaching objects of sergeant colleges are NCO students. Their intelligence characteristics are weak abstract thinking ability, strong image thinking ability, less heuristic teaching, and more interest teaching. We should make full use of the characteristics of practical teaching, such as 
flexibility, variety and intuition and image, to free teaching from dull book teaching and pure theoretical explanation, so as to improve learning initiative and enthusiasm. It can be regarded as an important evaluation index according to whether the interest and content of the classroom should be set up. Careful design of classroom links to inspire students' interest in learning in order to exchange the high quality and efficiency of the class teaching.

Secondly, combining the characteristics of the curriculum, the teaching method is added to the point of addition

Talent training aims at training NCO academies can meet the needs of the army military post back most of the course content is coherence and realistic point, skills practical knowledge, thus completely suitable for case teaching, situational teaching method applying in teaching practice, can be arranged in the teaching methods, enhance the guidance of evaluation. Especially the application of case teaching, for an instance, from first to last to learn from the shallower to the deeper theoretical foundation and practical skills in order to insert, so as to realize the practical teaching for the combination of theory teaching and practical training and unified. Through evaluation of teaching preparation, teachers should be encouraged to actively contact the troops, to collect materials widely, and to strengthen the preparation and application of cases. We should pay attention to the enrichment of teaching methods in practice teaching. We should not blindly request skilled operation, but also make comprehensive use of situational method, teaching method, case method and so on, so as to pursue the optimization and matching of teaching methods and teaching contents.

Thirdly, overall arrangement of content to highlight skill training as a point of addition

The practical teaching evaluation should pay more attention to improving the proportion of practical teaching, strengthen its dominant position and highlight the skill training. First, we should take the cultivation of professional post ability as the goal, reform the evaluation of practical teaching content, and advocate the compilation of practical training materials, mainly based on practical skills training, and divided into modules. The two is to increase the proportion of practical teaching. Advocating the reorganization and integration of professional courses and improving the proportion of practical teaching in the whole teaching plan, making the theoretical teaching and practice teaching achieve a reasonable proportion based on the premise of "enough knowledge". The three is the evaluation of the reform of practical teaching mode. The improvement of ability is not only taught, but also in practice. It is also realized in practice. Practical teaching evaluation should focus on advocating the teaching mode of "taking students as the main body", so that students can often stay in the practical environment and get real insights through personal experience in practice. The four is to improve the evaluation of teaching methods and methods. It advocates the use of modern teaching methods, such as virtual reality technology, to carry out virtual situational exercises and simulation exercises, and also can organize colorful practical activities and improve students' practical ability in activities.

Fourthly, close the quality of teaching and take strict teaching management as a point of addition

To promote practical teaching evaluation, we should set up teaching management indicators according to needs, improve the practice teaching evaluation system, avoid "practice" and "theory". First of all, we should advocate the establishment of a system of assessment and evaluation which is closely integrated with practical teaching. The purpose of practical teaching is to train the students' hands-on ability and to serve the demand of the troops. Therefore, the formulation of evaluation indicators must conform to reality, and scientifically design according to the characteristics of teaching and practice, according to all links, steps and final results of practical operation. Secondly, the standard of evaluation should be standardized on the certification of professional skills. At present, many NCO colleges and universities are connected with the curriculum and specialty, which can be evaluated according to the assessment of local core professional skills, vocational skills and occupation qualification certificates.

\section{References}

[1] Gu Liping. Chinese of higher education on the construction of teaching system [J]. practice in 
higher vocational colleges, 2005 (11).

[2] He Bing. Experimental science and technology [J]. evaluation research and practice of the training base in higher vocational colleges, 2008 (1). 